\title{
Development and validation of a HPLC method for estimation of loratadine and its application to a pharmacokinetic study
}

\author{
Nagadani Swarnalatha ${ }^{1, *}$ and Vidyavathi Maravajhala ${ }^{2}$ \\ ${ }^{1}$ Department of Pharmaceutics, Malla Reddy Pharmacy College, Hyderabad 500 014, India \\ ${ }^{2}$ Institute of Pharmaceutical Technology, Sri Padmavathi Mahila Visvavidyalayam, Tirupathi 517 502, India
}

\begin{abstract}
A simple, rapid, sensitive and accurate high-performance liquid chromatography method was developed and validated for the quantification of loratadine concentration in rabbit plasma using metoclopramide as an internal standard. Separation was performed on kromosil C18 column $(250 \times 4.6 \mathrm{~mm} 5 \mu \mathrm{m})$ using a mobile phase consisting of $0.1 \%$ perchloric acid : acetonitrile $(55: 45 \mathrm{v} / \mathrm{v})$ at a flow rate of $1 \mathrm{ml} / \mathrm{min}$. Validation of the method was performed in order to demonstrate its selectivity, linearity, precision, accuracy, ruggedness, recovery and matrix effect. The calibration curves of loratadine were linear over a concentration range of 5-1022 $\mu \mathrm{g} / \mathrm{ml}$. The with-in and between-day of coefficients of variation were $<10 \%$. The extraction recoveries of loratadine at the three levels of quality control samples were $99.961 \%, 99.767 \%$ and $99.938 \%$. The method was rapid with a retention time of loratadine and the internal standard observed at 6.67 and $8.83 \mathrm{~min}$ respectively. The developed method was successfully applied for studying the pharmacokinetics of loratadine in rabbits.
\end{abstract}

Keywords: HPLC, internal standard, loratadine, metoclopramide.

LORATADINE is an $\mathrm{H} 1$ histamine antagonist which belongs to the second generation of antihistamines and is helpful in treating allergies. It is closely related to tricyclic antidepressants in its structure, such as imipramine and is distantly related to the atypical antipsychotic quetiapine ${ }^{1}$. Loratadine is free from sedation at the recommended doses among the second generation anti-histamines ${ }^{2}$. Its chemical name is 4-(8-chloro-5,6-dihydro-11 H-benzo [5,6] cyclohepta [1,2-b] pyridine-11-ylidene)-1-piperidinecarboxylic acid ethyl ester ${ }^{3}$. Loratadine is a long-acting second generation histamine antagonist that is structurally similar to cyproheptadine and azatadine ${ }^{4}$. Loratadine opposes free histamines and exhibits specific, selective peripheral $\mathrm{H} 1$ antagonistic activity. This hinders the action of endogenous histamine, which subsequently leads to short-term relief from the negative symptoms (e.g. nasal congestion, watery eyes) caused by the histamine ${ }^{5}$.

*For correspondence. (e-mail: swarnalathanagadani@gmail.com)
Loratadine is satisfactorily absorbed from the gastrointestinal tract and has quick first-pass hepatic metabolism when given orally. It is metabolized by isoenzymes of the cytochrome P450 system, including CYP3A4, CYP2D6, and to a lesser extent, several others. A literature survey carried out on the estimation of loratadine in rabbit plasma revealed only few analytical methods ${ }^{6-8}$. However, there was no standard method for loratadine estimation in rabbit plasma by high-performance liquid chromatography (HPLC). Hence, an attempt has been made to develop a new method for the estimation and validation of loratadine in rabbit plasma in accordance with the United States Food and Drug Administration (USFDA) guidelines.

\section{Materials and method}

Loratadine and metoclopramide pure drug (API) samples were obtained from DR. Reddy's Laboratories Ltd, Hyderabad, India. All the chemicals and solvents like distilled water, acetonitrile, phosphate buffer, methanol, potassium dihydrogen orthophosphate buffer, orthophosphoric acid were obtained from RANKEM-Mumbai, India.

\section{Analytical method development - HPLC method}

In order to estimate loratadine content in the plasma samples, HPLC method was developed using different mobile phases in different ratios: $0.1 \%$ orthophosphoric acid : acetonitrile $(40: 60) ; 0.01 \mathrm{~N}$ potassium dihydrogen phosphate : acetonitrile $(55: 45) ; 0.1 \%$ perchloric acid: acetonitrile $(55: 45)$. Different chromatographic columns were used (azilent C18 $250 \mathrm{~mm} \times 4.6 \mathrm{~mm} 5 \mu$, BDS C18 $150 \mathrm{~mm} \times 4.6 \mathrm{~mm} 5 \mu$, kromosil C18 $250 \mathrm{~mm} \times 4.6 \mathrm{~mm}$ $5 \mu$ ). Based on peak shape, retention time, tailing factor, the chromatographic conditions were optimized.

\section{Preparation of loratadine stock and spiking solutions}

The stock solution of loratadine was prepared by dissolving the drug in diluents (water:acetonitrile; 50:50) to produce $1 \mathrm{mg} / \mathrm{ml}$. 


\section{RESEARCH ARTICLES}

From this stock solution, $0.012,0.029,0.094,0.534$, $1.150,1.412,1.860$ and $2.350 \mathrm{ml}$ were pipetted and transferred to eight individual $10 \mathrm{ml}$ volumetric flasks and the volume was made up to the mark with diluent (water: acetonitrile; $50: 50$ ) to produce $1.20,2.90,9.40,53.40$, $115,141.20,186$ and $235.0 \mu \mathrm{g} / \mathrm{ml}$ concentrations. Calibration standards and quality control (QC) samples were prepared by spiking blank plasma with working stock dilutions of analytes to produce $0.005,0.013,0.041,0.232$, $0.500,0.614,0.809$ and $1.022 \mu \mathrm{g} / \mathrm{ml}$ concentrations.

\section{Preparation of internal standard (IS) solution}

$10 \mathrm{mg}$ of metoclopramide was taken in $10 \mathrm{ml}$ volumetric flask and the volume was made with diluent (water: acetonitrile 50:50). From this stock solution, $0.1 \mathrm{ml}$ of solution was taken into $10 \mathrm{ml}$ volumetric flask and made up the volume with the same diluent to produce $10 \mu \mathrm{g} / \mathrm{ml}$ solution.

\section{Buffer preparation ( $0.1 \%$ perchloric acid)}

$1 \mathrm{ml}$ of perchloric acid was taken in $1000 \mathrm{ml}$ volumetric flask and the solution was made up using HPLC grade water to produce $1000 \mathrm{ml}$.

Extraction procedure: $250 \mu \mathrm{l}$ of plasma, $50 \mu \mathrm{l}$ of IS and $10 \mu \mathrm{l}$ of loratadine spiking solutions were taken into a centrifugal tube and $2 \mathrm{ml}$ of acetonitrile was added. The solution was kept in a cyclomixer for $15 \mathrm{sec}$ and vortexed for $2 \mathrm{~min}$ followed by centrifugation for $3 \mathrm{~min}$ at $3200 \mathrm{rpm}$. After centrifugation, the supernatant liquid was collected and $50 \mu \mathrm{l}$ was injected directly into HPLC column.

Method validation: The optimized chromatographic method was completely validated according to the procedures described in USFDA guidelines for the validation of analytical methods and stability testing of the new drug respectively. The method was validated for different parameters such as system suitability, sensitivity, linearity, precision, accuracy, ruggedness, recovery, matrix effect, etc.

Sensitivity: Sensitivity was checked by preparing six lower limit of quantitation (LLOQ) samples independent of calibration curve standards.

Linearity: Calibration curves were obtained daily for three days using standards containing eight different concentrations. Curves were constructed by calculating the ratios of peak-area of loratadine to that of IS. For the preparation of calibration standards, working solutions of loratadine $(50 \mu \mathrm{l})$ and IS $(50 \mu \mathrm{l})$ were added to blank plasma $(500 \mu \mathrm{l})$ to obtain final concentrations of 0.005 , $0.013,0.041,0.232,0.500,0.614,0.809$ and $1.022 \mu \mathrm{g} / \mathrm{ml}$.
Precision and accuracy studies: The accuracy and precision evaluation were assessed by repeated analysis of rabbit $\mathrm{K}_{2}$ EDTA plasma samples containing different concentrations of loratadine on separate occasions. A single run consisted of a calibration curve, six replicates of LLOQ, low-quality control (LQC), medium quality control (MQC) and high-quality control (HQC) samples.

Ruggedness: Ruggedness was performed by different analyses. The run consisted of a calibration curve and a total of six spiked samples; six replicates of each of LLOQ, LQC, MQC and HQC samples.

Recovery: Recovery of loratadine was evaluated by comparing mean analyte responses of six extracted samples of LQC, MQC and HQC samples to mean analyte response of six replicates injection of an unextracted quality control sample.

Matrix effect: Eighteen blank matrix samples from six different lots of matrices were processed. The reconstituted blank samples were spiked with HQC and LQC level (from each lot one blank, one HQC and one LQC sample) and compared against corresponding HQC and LQC samples injected in six replicates.

\section{Pharmacokinetic studies}

Healthy rabbits (New Zealand albino) of either sex weighing 2-3 kg were selected and housed with CPCSEA guidelines ${ }^{9}$. The animals were fasted overnight prior to treatment but had free access to water. None of the subjects received any other drug for at least two weeks

Table 1. Composition of loratadine test formulation (oral disintegrating tablets)

\begin{tabular}{lc}
\hline Compound & Quantity (mg) \\
\hline Granules (containing loratadine $10 \mathrm{mg})$ & 40 \\
Sodium starch glycolate & 18 \\
Mannitol & 130 \\
Aspartame & 2 \\
Magnesium stearate & 5 \\
Talc & 5 \\
Total weight & 200 \\
\hline
\end{tabular}

Table 2. Optimized chromatographic conditions

\begin{tabular}{ll}
\hline Name & \multicolumn{1}{c}{ Parameters } \\
\hline Column & Kromasil C18 column $(250 \times 4.6 \mathrm{~mm}, 5 \mu)$ \\
Mobile phase composition & $\begin{array}{c}0.1 \% \text { Perchloric acid buffer : acetonitrile } \\
(55: 45)\end{array}$ \\
Flow rate & $1 \mathrm{ml} / \mathrm{min}$ \\
Injection volume & $50 \mu 1$ \\
Run time & $12 \mathrm{~min}$ \\
Detection wavelength & $280 \mathrm{~nm}$ \\
Column temperature & $30^{\circ} \mathrm{C}$ \\
Diluent & Water : acetonitrile $(50: 50)$ \\
\hline
\end{tabular}



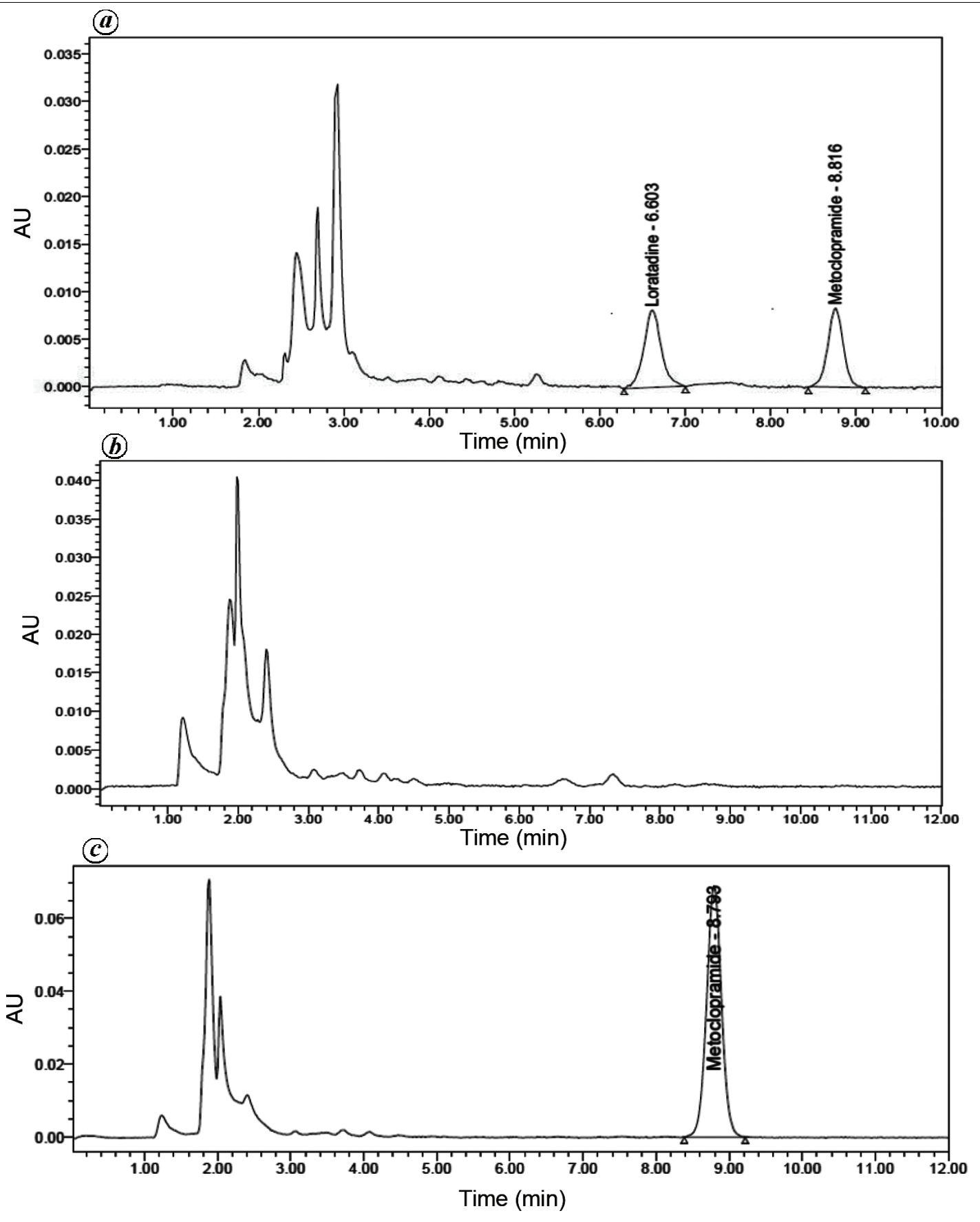

Figure 1. $\boldsymbol{a}$, Optimized chromatogram of loratadine and ISTD. $\boldsymbol{b}$, Blank chromatogram. $\boldsymbol{c}$, ISTD chromatogram.

before the commencement of the study and no other drug was given during the entire study ${ }^{10,11}$.

Experimental design: Animals were separated into three experimental groups and each group consisted of three animals $(n=3)$. The test formulation of the batch was compared with reference/marketed formulation by the following treatment schedule under fasting condition. Group I-(Normal control) - received placebo; Group II - (Positive control) - reference formulation; Group III - (Sample) - loratadine test formulation.

\section{Drug administration and sampling procedure}

The test and reference formulations were administered via oral gauge at a dose of $0.164 \mathrm{mg}$ loratadine (Table 1). Based on the conversion factor of adult dose to rabbit dose, the dose was calculated as shown below ${ }^{12,13}$.

$$
\begin{aligned}
\operatorname{HED}(\mathrm{mg} / \mathrm{kg})= & \operatorname{animal} \text { dose }(\mathrm{mg} / \mathrm{kg}) \times \\
& \text { animal } \mathrm{Km} \text { factor/human } \mathrm{Km} \text { factor. }
\end{aligned}
$$

HED $=$ human equivalent dose; animal $K m$ factor $=12$ and human $K m$ factor $=37$. 
RESEARCH ARTICLES

Table 3. Validated parameters of loratadine by HPLC method in plasma

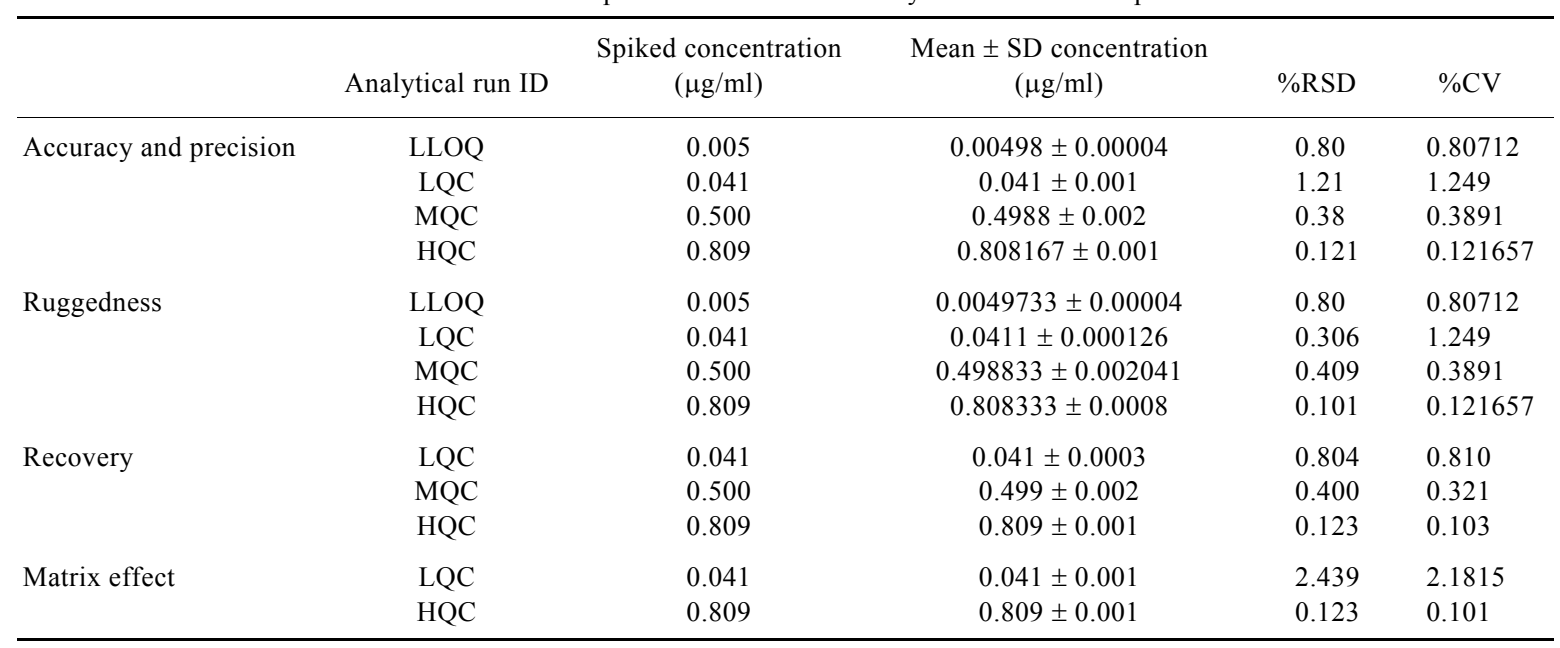

Table 4. Data for calibration curve

\begin{tabular}{lc}
\hline Concentration $(\mu \mathrm{g} / \mathrm{ml})$ & Area response ratio \\
\hline 0.005 & 0.0077 \\
0.013 & 0.0145 \\
0.041 & 0.0225 \\
0.232 & 0.0733 \\
0.500 & 0.1453 \\
0.614 & 0.1754 \\
0.809 & 0.2287 \\
1.022 & 0.2883 \\
\hline
\end{tabular}

Table 5. Plasma concentration values of loratadine formulations

\begin{tabular}{lcc}
\hline & \multicolumn{2}{c}{ Concentration $(\mathrm{ng} / \mathrm{ml})$} \\
\cline { 2 - 3 } Time $(\mathrm{h})$ & Test formation & Reference formation \\
\hline 0 & 0 & 0 \\
0.25 & $0.88 \pm 0.03$ & $0.82 \pm 0.017$ \\
0.5 & $1.52 \pm 0.06$ & $1.23 \pm 0.200$ \\
1 & $9.36 \pm 0.20$ & $6.5 \pm 0.321$ \\
1.5 & $11.84 \pm 0.10$ & $9.5 \pm 0.752$ \\
2 & $8.29 \pm 0.10$ & $6.8 \pm 0.395$ \\
2.5 & $6.86 \pm 0.152$ & $5.03 \pm 0.351$ \\
3 & $5.06 \pm 0.350$ & $3.25 \pm 0.208$ \\
4 & $3.93 \pm 0.360$ & $2.1 \pm 0.404$ \\
6 & $2.41 \pm 0.264$ & $1.6 \pm 0.256$ \\
8 & $1.26 \pm 0.050$ & $1.243 \pm 0.262$ \\
10 & $1.04 \pm 0.090$ & $1.106 \pm 0.27$ \\
12 & $0.96 \pm 0.10$ & $0.8 \pm 0.236$ \\
24 & $0.82 \pm 0.12$ & $0.79 \pm 0.22$ \\
\hline
\end{tabular}

The protocol was approved by the institutional animal ethical committee at Malla Reddy Institute of Pharmaceutical Sciences (1662/PO/Re/S/12/CPCSEA), Andhra Pradesh, India. The experiments were conducted as per CPCSEA guidelines.

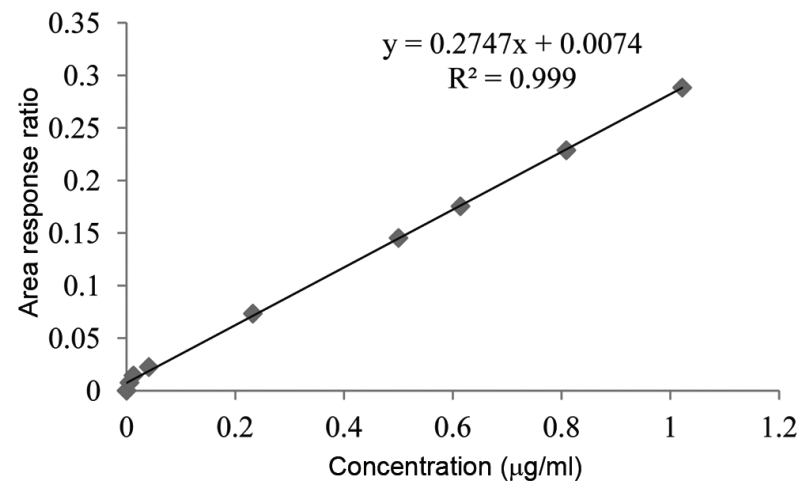

Figure 2. Calibration curve of loratadine in plasma.

The blood samples (each about $2 \mathrm{ml}$ ) were drawn at 0 , $0.25,0.5,1,1.5,2,2.5,3,4,6,8,10,12$ and $24 \mathrm{~h}$ after administration of formulation from the marginal ear vein of the rabbits held in the wooden box ${ }^{14}$. The collected blood samples were immediately centrifuged at $5000 \mathrm{rpm}$ in an ultra cooling centrifuge for $10 \mathrm{~min}$ at $4{ }^{\circ} \mathrm{C}$. The supernatant plasma sample was separated and stored in a clean screw capped $5 \mathrm{ml}$ polypropylene plasma tube at $-20^{\circ} \mathrm{C}$ in a deep freezer, until further analysis ${ }^{15}$.

\section{Extraction of the drug from rabbit plasma}

The stored plasma samples were processed at room temperature, $250 \mu \mathrm{l}$ of plasma was added to $500 \mu \mathrm{l}$ of acetonitrile to precipitate the proteins. The samples were vortexed on a vortex mixer for $15 \mathrm{~min}$, followed by centrifugation at $10,000 \mathrm{rpm}$ for $15 \mathrm{~min}$. The respective samples were then injected into the HPLC column.

Pharmacokinetic analysis: The plasma concentrations were used to construct pharmacokinetic profiles by plotting drug concentration-time curves. To determine the 


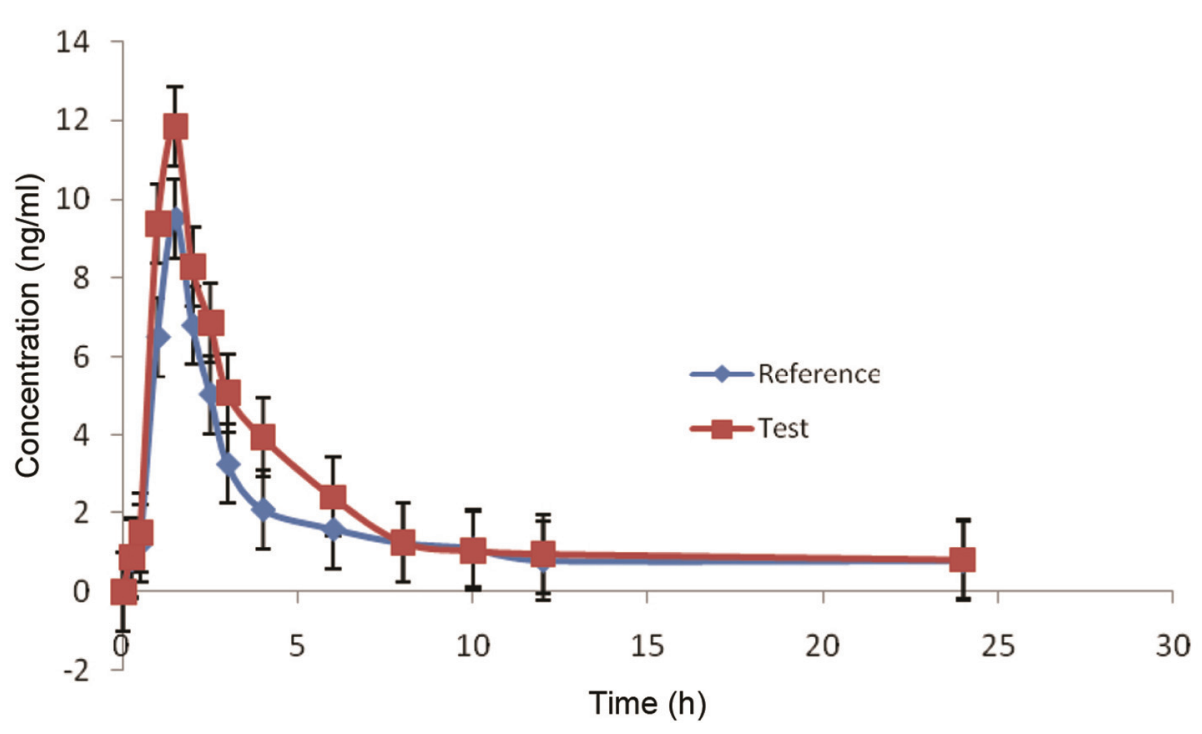

Figure 3. Plasma concentration-time profile.

Table 6. Pharmacokinetic parameters of loratadine formulations

\begin{tabular}{lcc}
\hline $\begin{array}{l}\text { Pharmacokinetic } \\
\text { parameter }\end{array}$ & Test formulation & Reference formulation \\
\hline$C_{\max }(\mathrm{ng} / \mathrm{ml})$ & $11.84 \pm 0.296$ & $9.5 \pm 0.430$ \\
$T_{\max }(\mathrm{h})$ & $1.5 \pm 0.62$ & $1.5 \pm 0.64$ \\
$\mathrm{AUC}_{0-24}(\mathrm{mg} \mathrm{h} / 1)$ & $49.71 \pm 1.01$ & $38.4 \pm 0.6$ \\
$\mathrm{AUC}_{0-\infty}(\mathrm{mg} \mathrm{h} / \mathrm{l})$ & $50.89 \pm 1.52$ & $39.53 \pm 1.02$ \\
$\left.\mathrm{Kel}_{(\mathrm{h}}^{-1}\right)$ & $0.11 \pm 0.23$ & $0.28 \pm 0.56$ \\
$T_{1 / 2}(\mathrm{~h})$ & $6.47 \pm 0.10$ & $6.31 \pm 0.31$ \\
\hline
\end{tabular}

pharmacokinetic parameters, all data obtained subsequently were fed into pharmacokinetic software 'WinNonlin ${ }^{\circledR}$. The pharmacokinetic parameters such as maximum plasma concentration $\left(C_{\max }\right)$, time to reach maximum concentration $\left(T_{\max }\right)$, area under the curve $\left(\mathrm{AUC}_{0}-t\right)$ and $\left(\mathrm{AUC}_{0-\infty}\right)$, elimination rate constant (Kel) and biological half-life $\left(t_{1 / 2}\right)$ were calculated.

\section{Results and discussion}

After estimating loratadine using different mobile phases with different ratios and by using different columns, the final optimized chromatographic conditions were developed as shown in Table 2 and the respective chromatograms by these conditions are given in Figure 1 .

\section{Method validation}

System suitability: The retention times and area of loratadine and ISTD were measured. The per cent coefficients of variation $(\mathrm{CV})$ of area ratio was found to be 1.34 and within the acceptable limits.
Sensitivity: Six LLOQ samples were prepared independent of calibration curve standards. The per cent $\mathrm{CV}$ of an area was found to be 1.14 and within the acceptable limits.

Accuracy and precision, ruggedness, recovery, matrix effect: The range of per cent $\mathrm{CV}$ for accuracy and precision was found to be from 0.12 to 1.24 . The range of between-run nominal value percentage was found to be from 99.66 to 100.81 . The range of within-run per cent $\mathrm{CV}$ for ruggedness was found to be from 0.1 to 0.8 . Its nominal values percentage ranged from 99.73 to 100.24 . The mean recovery values were $99.93 \%, 99.76 \%$ and $99.96 \%$ at HQC, MQC and LQC respectively. No outcome of quantitation for loratadine and IS was observed in the matrix effect. The results for accuracy and precision, ruggedness, recovery and matrix effect are given in Table 3.

Linearity and calibration curves: Calibration curves were found to be consistently accurate and precise in the range of 0.005 to $1.022 \mu \mathrm{g} / \mathrm{ml}$ for loratadine. The regression coefficient $(r)$ was equal to 0.999 . Reversecalculations were made from the calibration curves to determine loratadine concentration of each calibration standard. The corresponding data are presented in Table 4. A typical calibration curve is presented in Figure 2.

The plasma concentration-time profile values are given in Table 5 and the plasma concentration-time profile curve is given in Figure 3.

The pharmacokinetic parameters of loratadine test and reference formulations are shown in Table 6. AUC is an important parameter for comparative bioavailability studies. However, the other two parameters $C_{\max }, T_{\max }$ are also important features and could affect the therapeutic behaviour of a drug. And hence were also considered in 


\section{RESEARCH ARTICLES}

this study. There was no difference in $T_{\max }$, half-life $\left(t_{1 / 2}\right)$ and elimination rate $(\mathrm{Kel})$ of test and reference formulations. $C_{\max }$ and total bioavailability $\left(\mathrm{AUC}_{0-24}\right.$ and $\left.\mathrm{AUC}_{0-\infty}\right)$ of test formulation were high compared to reference formulation. Thus the test formulation was successful in increasing bioavailability.

\section{Conclusion}

A simple, sensitive, accurate and precise HPLC method was developed and validated for the estimation of loratadine in rabbit plasma. The present method was successfully applied in the pharmacokinetic study of loratadine in rabbit plasma, in which all the pharmacokinetic parameters were determined. $C_{\max }, T_{\max }, \mathrm{AUC}, \mathrm{Kel}, t_{1 / 2}$ were measured. $C_{\max }$ and the total bioavailability $\left(\mathrm{AUC}_{0-24}\right.$ and $\mathrm{AUC}_{0-\alpha}$ ) were high for test formulation compared to reference formulation. From the results of pharmacokinetic studies, it was thus concluded that the test formulation was better than reference formulation as it showed a greater extent of absorption.

1. Devi, D. K. N., Rao, N. N., Mounika, G. V., Geeta Priyanka, K. and Naga Deepika, K., Preparation and evaluation of loratadine tablets by using novel polacrilin potassium. Der. Pharm. Lett., 2015, 7(5), 200-204.

2. Maslarska, V. and Peikova, L., HPLC determination and validation of loratadine in pharmaceutical preparations. IJBPAS, 2013, 2(12), 2181-2191.

3. Graul, A., Leeson, P. A. and Castaoer, J., Desloratadine treatment of allergic rhinitis, histamine H1 antagonist. Drug Future, 2000, 25, 339-443.

4. Barenholtz, H. A. and McLeod, D. C., Loratadine, a nonsedating antihistamine with once-daily dosing. DICP, 1989, 23(6), 445450 .
5. Roman, I. J., Kassem, N., Gural, R. P. and Herron, J., Suppression of histamine-induced wheal response by loratadine (SCH 29851) over 28 days in man. Ann. Allergy, 1986, 57(4), 253-256.

6. Elkomy, M. H., El Menshawe, S. F., Abou-Taleb, H. A. and Elkarmalawy, M. H., Loratadine bioavailability via buccal transferosomal gel: formulation, statistical optimization, in vitro/in vivo characterization, and pharmacokinetics in human volunteers. Drug Deliv., 2017, 24(1), 781-791.

7. Radhakrishna, T., Narasaraju, A., Ramakrishna, M. and Satyanarayana, Simultaneous determination of montelukast and loratadine by HPLC and derivative spectrophotometric methods. J. Pharm. Biomed. Anal., 2003, 31(2), 359-368.

8. Ramulu, G., Ravindra Kumar, Y., Vyas, K., Suryanarayana, M. V. and Mukkanti, K., A new validated liquid chromatographic method for the determination of loratadine and its impurities. Sci. Pharm., 2011, 79(2), 277-291.

9. CPCSEA Guidelines for laboratory animal facility. Indian J. Pharmacol., 2003, 35, 257-274.

10. Sangeetha, S. et al., Pharmacokinetic evaluation of quinine in tablet formulation from herbal extracts. Int. J. Biopharm., 2011, 2(1), 1-7.

11. Sangeetha, S. and Samanta, M. K., Determination of pharmacokinetic parameters for Atropa belladonna extract containing atropine in tablet dosage form. Asian J. Pharm. Clin. Res., 2016, 9(3), 5761.

12. Ghosh, M. N., Fundamentals of Experimental Pharmacology, SK Ghosh Publications, Kolkata, 2005, 3rd edn, pp. 192-194.

13. Shin, J.-W., Seol, I.-C. and Son, C.-G., Interpretation of animal dose and human equivalent dose for drug development. J. Korean Oriental Med., 2010, 31(3), 1-7.

14. Ahmad, M., Iqbal, M., Akhtar, N. and Murtaza, G., Comparison of bioavailability and pharmacokinetics of diclofenac sodium and diclofenac potassium in healthy and Escherichia coli induced febrile rabbits. Pak. J. Zool., 2010, 42(4), 395-400.

15. Neelima Rani, T. et al., Formulation and evaluation of Simvastatin rapid melts. Ijppr. Human, 2016, 7(1), 554-573.

Received 29 August 2018; revised accepted 4 October 2018

doi: $10.18520 / \mathrm{cs} / \mathrm{v} 116 / \mathrm{i} 2 / 243-248$ 